УДК $661.666+661.183 .2$

\author{
І.Г. Рослик ${ }^{1}$, В.В. Загородна ${ }^{1}$ \\ ${ }^{1}$ Національна металургійна академія України
}

\title{
ДОСЛІДЖЕННЯ ВЛАСТИВОСТЕЙ НАНОПОРИСТОГО ВУГЛЕЦЮ, ОТРИМАНОГО 3 КАРБІДІВ РІЗНОЇ БУДОВИ
}

\begin{abstract}
На підставі функціональної теорії нелокальної щільності (NLDFT) досліджений зв'язок між початковою структурою карбідів та пористою структурою синтезованих 3 них вуглецю. Нанопористий вуглець одержували високотемпературною обробкою порошків карбідів з різною будовою потоком хлору на експериментальній установці проточного типу. Експериментально встановлено, що використання карбідів 3 кубічною граткою забезпечує отримання нанопористого вуглецю з контрольованими розмірами пор у межах від 0,5 до 2 нм та достатньо високою питомою поверхнею. Самий високий об'єм мікропор та висока питома поверхня $1247 \mathrm{~m}^{2} / \Gamma$ спостерігається у вуглецю, що отриманий з карбіду титану з гранецентрованою кубічною граткою. Вуглець, синтезований 3 карбіду заліза $\mathrm{Fe}_{3} \mathrm{C}$ з ромбічною граткою, має найменший об'єм мікропор та самий широкий діапазон розподілу пор за розмірами (від 0,8 до 20 нм). Результати роботи можуть бути використані для синтезу вуглецю для виготовлення електродів суперконденсаторів.
\end{abstract}

DOI: $10.34185 / 0543-5749.2020-1-25-32$

\section{Вступ}

Зі стрімким розвитком електротехніки та електроніки велика увага приділяється створенню різних електрохімічних систем, придатних для вироблення і зберігання енергії. Важливе місце серед джерел енергії належить електрохімічним конденсаторам (іоністорам або суперконденсаторам). Так суперконденсатори (СК) займають проміжне місце між акумуляторами, які здатні накопичувати високу електричну енергію, та електричними конденсаторами, які здатні віддавати високу потужність протягом декількох мілісекунд [1-2]. Для досягнення високої ємності СК необхідне використання електродів 3 високою питомою поверхнею і електронною провідністю. В якості активної речовини в електродах суперконденсаторів подвійного шару i гібридних системах може бути придатний новий тип вуглецевих матеріалів, а саме нанопористий вуглець (НПВ). Він відноситься до класу каталітичних активних вуглецевих матеріалів зі структурою, менш впорядкованої, ніж графіт, але й не повністю аморфною.

Вуглецеві матеріали для суперконденсаторів повинні мати високу пористість, розвинену питому поверхню в межах від 1000 до $2000 \mathrm{~m}^{2} / \Gamma$, і контрольований розмір пор в межах $0,7-10$ нм, тобто порівнянні з іонами електроліту $[2,3]$. Якщо пори вуглецю занадто малі, іони електроліту не зможуть зайняти місця у порах, а якщо занадто великі - іони електроліту легко отримують доступ до поверхні пор, але загальна площа їх поверхні при цьому зменшується.

Нанопористий вуглець можна синтезувати 3 рослинної сировини [4-7], фенольних смол [8], а також з вуглецевих нанотрубок $[9,10]$. Розмір пор, їх розподіл за розмірами, регулярність або хаотичність розподілу в об'ємі істотно впливають на властивості наноматеріалів. Спрямоване створення регулярних структур із заданими розмірами і формою пор - один 3 найважливіших напрямків формування наноматеріалів. При отримані вуглецю із полімеру і природних матеріалів важко контролювати розподіл пор за розмірами через випадкову орієнтацію полімерних ланцюгів, їх форму і структурну неоднорідність [11].

Одним зі способів, що дозволяє отримувати вуглець 3 контрольованою пористістю, є обробка карбіду металу або неметалу хлором при високій температурі. У зарубіжній літературі для

(C) Рослик І.Г., Загородна В.В., 2020 
назви такого продукту використовують термін carbide-derived carbon (CDC) $[12,13]$. Згідно публікаціям останніх часів для синтезу нановуглецю можна використовувати металоподібні карбіди перехідних металів IV-VII груп та ковалентні карбіди неметалів (бору, кремнію). При застосуванні карбідів з різними типами і параметрами кристалічної решітки вдається формувати пори різного контрольованого розміру i об'єму, тобто управляти пористістю вуглецю, що дуже важливо для властивостей суперконденсаторів [14]. Метою даної роботи є визначення зв'язку між вихідною структурою карбіду та пористою структурою синтезованого 3 нього вуглецю. Завдання досліджень - оцінити, яким чином тип кристалічної гратки карбіду впливає на розмір пор, величину питомої поверхні та розподіл пор за розмірами у нанопористому вуглецю.

\section{Методика}

Зразки високопористого вуглецю синтезували шляхом обробки порошків карбідів кремнію, титану, ванадію, бору, молібдену та заліза безперервним потоком хлору при температурах $800-1000{ }^{\circ} \mathrm{C}$ на експериментальній установці. Згідно 3 реакцією (1) відбувається селективна екстракція атомів металу 3 кристалічної гратки карбіду та перебудова структури карбіду у чистий вуглець:

$$
\mathrm{Me}_{\mathrm{a}} \mathrm{C}_{\mathrm{b}}(\mathrm{T})+\mathrm{c} / 2 \mathrm{Cl}_{2}(\Gamma)=\mathrm{a} \mathrm{MeCl}_{\mathrm{c}}(\Gamma)+\mathrm{bC}(\mathrm{T}) \text {. }
$$

Вихідний карбід, який завантажують в горизонтальну трубчасту піч 3 кварцевою трубою, продувають аргоном протягом 30 хв 3 подальшим нагріванням до потрібної температури зі швидкістю $30{ }^{\circ} \mathrm{C} /$ хв. Після досягнення необхідної температури потік аргону зупиняють, та вмикають потік хлору. По закінченню процесу хлорування зразок охолоджують в середовищі аргону для видалення залишкових хлоридів металів. Дуже важливо, щоб у реакційному просторі був повністю відсутній кисень. Наявність кисню у реакційному просторі підвищує зольність вуглецю, що знижує якість електродного матеріалу для суперконденсаторів. Залишки хлору в отриманому вуглецю видаляють шляхом відпалювання у середовищі водню при температурі $500-600^{\circ} \mathrm{C}$ згідно з реакцією

$$
\mathrm{H}_{2}+\mathrm{Cl}_{2} \rightarrow 2 \mathrm{HCl} \text {. }
$$

Молекула водню завдяки малому розміру (0,25 нм) здатна видаляти 3 мікропор матеріалу залишки хлору, діаметр молекули якого складає 0,37 нм.

Текстурні характеристики зразків пористого вуглецю визначені методом низькотемпературної адсорбції-десорбції азоту на автоматичному високоточному обладнанні (Quantachrome, США) 3 комп'ютерним керуванням та обробкою даних. Для визначення питомої поверхні застосовували метод Брунауера - Еммета-Теллера (БЕТ), який оснований на адсорбції газу - азоту [15-16]. Для аналізу мікропор застосовували метод функціонала щільності DFT.

Пористу структуру вуглецю, а саме об'єм пор та їх розподіл за розмірами, було визначено за допомогою функціональної теорії нелокальної щільності (NLDFT) 3 використанням програмного забезпечення, що додається до прибору. Загальний об'єм та розподіл мікропор за розмірами визначали за допомогою методу СаітоФоллей (SF).

\section{Результати та їх обговорення}

Важливою характеристикою карбідів $є$ взаємодія метал-вуглець і геометрія проміжків між вузлами кристалічної гратки. Атоми металу в карбідах часто утворюють прості структури: гранецентровану кубічну (ГЦК), гексагональну щільноупаковану (ГПУ), просту гексагональну (ГП) або змішані групи, що складаються 3 комбінації вищевказаних груп. Кристалічні структури карбідів перехідних металів можна описати як щільні (або близькі до них) упаковки металевих атомів, між вузлах яких впроваджені згідно $з$ правилом Хегга невеликі атоми вуглецю. У більшості структур відсутні помітні локалізовані взаємодії C-C, які характерні для органічних сполук. Метали підгрупи IVa утворюють монокарбіди, які кристалізуються в ГЦК гратки типу $\mathrm{NaCl}$. Для цих карбідів характерні широкі області гомогенності і стабільність. Карбід кремнію ( -SiC) належить до сполуки iз переважно ковалентним типом хімічних зв'язків i утворює кубічну кристалічну структуру, що східна зі структурою алмазоподібних фаз. Кристалічна решітка карбіду бору містить ікосаедри, всередині кожного з яких розташовується лінійне угруповання 3 трьох пов'язаних атомів вуглецю, відстань між якими становить 0,137 нм [17]. Карбід заліза $\left(\mathrm{Fe}_{3} \mathrm{C}\right)$ має ромбічну гратку, в вузлах якої розташовані атоми заліза, а в призма- 
тичних порах знаходяться атоми вуглецю. Найсильніший зв'язок між атомами заліза $\mathrm{Fe}-\mathrm{Fe}$, зв'язок Fе-C згідно з даними [18], в півтора рази слабший, а зв'язок С-С вкрай малий.
Властивості вихідних карбідів і параметри їх граток представлені в таблиці 1 [19].

Таблиця 1. Властивості вихідних карбідів

\begin{tabular}{|c|c|c|c|c|c|c|}
\hline $\begin{array}{l}\text { Формула } \\
\text { карбіду }\end{array}$ & Сінгонія & $\begin{array}{c}\text { Параметр } \\
\text { решітки, } \AA\end{array}$ & $\begin{array}{c}\text { Атомний } \\
\text { радіус, } \\
r_{M e}, \AA\end{array}$ & $\begin{array}{c}\text { Вміст } \\
\text { вуглецю, } \\
\text { \% ат. }\end{array}$ & $\begin{array}{c}\text { Щільність, } \\
\Gamma / \mathrm{cm}^{3}\end{array}$ & $\mathrm{~T}_{\text {плл }},{ }^{\circ} \mathrm{C}$ \\
\hline $\mathrm{SiC}$ & кубічна & $a=4,3596$ & 1,32 & 50 & 3,21 & $\begin{array}{c}2540 \\
\text { (з розклад.) }\end{array}$ \\
\hline $\mathrm{TiC}$ & кубічна & $a=4,3178$ & 1,47 & 50 & 4,92 & 3257 \\
\hline $\mathrm{VC}$ & кубічна & $a=4,118$ & 1,34 & 50 & 5,48 & 2648 \\
\hline $\mathrm{B}_{4} \mathrm{C}$ & ромбоедрічна & $a=5,19$ & 0,80 & 20 & 2,52 & $\begin{array}{c}2450 \\
\text { (з розклад.) }\end{array}$ \\
\hline $\mathrm{Mo}_{2} \mathrm{C}$ & гексагональна & $\begin{array}{l}a=2,997 \\
c=4,727\end{array}$ & 1,39 & 33,33 & 9,18 & 2522 \\
\hline $\mathrm{Fe}_{3} \mathrm{C}$ & ромбічна & $\begin{array}{c}a=4,5235 \\
b=5,089 \\
c=6,7353\end{array}$ & 1,26 & 25 & 7,69 & 1650 \\
\hline
\end{tabular}

За результатами ізотерм адсорбції вуглець, отриманий $з$ карбідів, що мають кубічну решітку ( $\mathrm{TiC}, \mathrm{SiC}$ та VC), відноситься до мікропористих систем. Про це свідчить ізотерма адсорбції азоту типу I. Для вуглецю, отриманого з карбідів бора $\mathrm{B}_{4} \mathrm{C}$ та карбіду молібдену $\mathrm{Mo}_{2} \mathrm{C}$, спостерігається типова ізотерма адсорбції азоту типу IV, що свідчить про наявність мезопор. Для зразків вуглецю, синтезованих 3 карбіду заліза, отримана ізотерма газової адсорбції типу II, що характерно для непористих твердих тіл або макропористим адсорбентам. Ці результати збігаються із даними таблиці 2 щодо розміру та об’єму пор. За даними таблиці 2 вуглець, що отриманий $з$ карбіду титану та карбіду ванадію, має найбільшу частку мікропор від загальної пористості, а саме $87 \%$ та $83 \%$, відповідно. Найменший вміст мікропор в НПВ, отриманому 3 карбіду заліза (16\%). Крім того у такого вуглецевого матеріалу найнижчі значення питомої поверхні та відносно великий середній діаметр пор.

Таблиця 2. Властивості пористого вуглецю

\begin{tabular}{|c|c|c|c|c|c|c|}
\hline \multirow{2}{*}{$\begin{array}{l}\text { Вихідний } \\
\text { карбід }\end{array}$} & \multicolumn{2}{|c|}{$\begin{array}{c}\text { Питома поверхня } \\
\text { за методом }\end{array}$} & \multirow{2}{*}{$\begin{array}{c}\text { Середній } \\
\text { діаметр } \\
\text { пор, нм }\end{array}$} & \multicolumn{2}{|c|}{ Об'єм пор,см³/г } & \multirow{2}{*}{$\begin{array}{c}\text { Тип ізотерми } \\
\text { адсорбції азоту }\end{array}$} \\
\hline & БЕТ, $\mathrm{m}^{2} / \Gamma$ & DFT, $\mathrm{M}^{2} / \Gamma$ & & Загальний & Мікропор & \\
\hline $\mathrm{SiC}$ & 1871 & 2120 & 4,988 & 2,333 & 0,734 & I \\
\hline $\mathrm{TiC}$ & 1247 & 1780 & 2,142 & 0,667 & 0,581 & I \\
\hline $\mathrm{VC}$ & 349,8 & 477,9 & 2,227 & 0,195 & 0,161 & $\mathrm{I}$ \\
\hline $\mathrm{B}_{4} \mathrm{C}$ & 1772 & 1494 & 2,848 & 1,262 & 0,521 & IV \\
\hline $\mathrm{Mo}_{2} \mathrm{C}$ & 1816 & 1632 & 3,371 & 1,530 & 0,562 & IV \\
\hline $\mathrm{Fe}_{3} \mathrm{C}$ & 32,86 & 32,42 & 8,494 & 0,069 & 0,011 & II \\
\hline
\end{tabular}

Найбільш високі значення питомої поверхні характерні для зразків вуглецю, що були отримані з карбіду кремнію та карбіду молібде- ну, але у таких зразків частка мікропор складає відповідно лише 31,5 \% та 36,7 \%.

На рисунку 1 представлені криві розподілу пор за розмірами у зразків вуглецю, синтезова- 
ного 3 карбідів різною будовою структур. Аналіз кривих показує, що у карбідів (TiC, VC, SiC) 3 кубічною кристалічною граткою спостерігається вузький інтервал розподілу пор за розміром, а саме від 0,5 до 3 нм. Це пов'язано 3 рів- номірним розподілом вуглецю у гратці. У вуглецю 3 карбіду титану спостерігається самий вузький інтервал розподілу розмірів пор у межах до 2 нм.
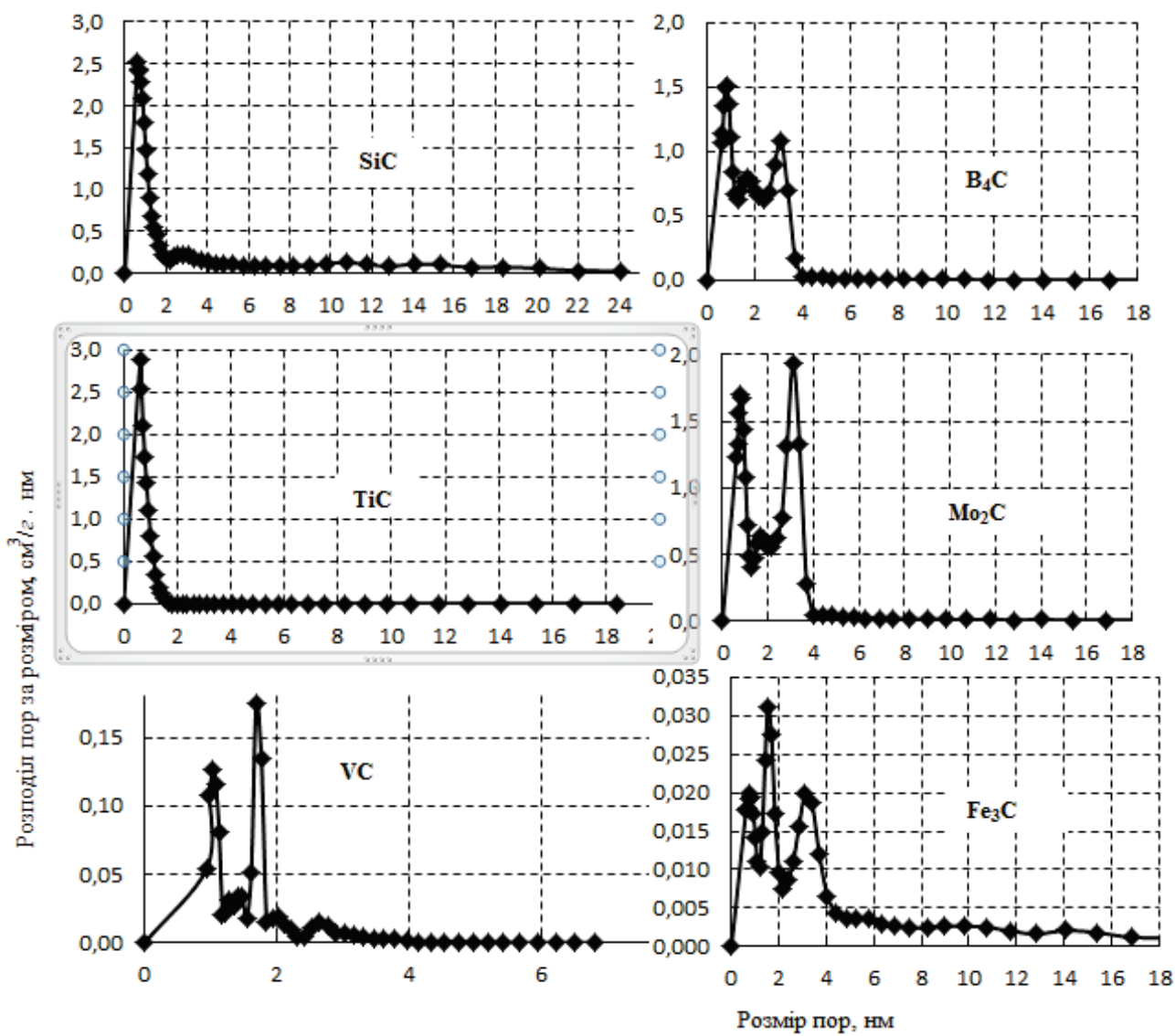

Рис. 1. Розподіл пор за розміром у НПВ, отриманих з різних карбідів

Зразки вуглецю, що отримані 3 карбіду $\mathrm{B}_{4} \mathrm{C}$ 3 ромбоедрічною та $3 \mathrm{Mo}_{2} \mathrm{C} 3$ гексагональною гратками, мають більш широкі інтервали розподілу пор за розмірами, що можна пояснити більшою та нерівномірною відстанню між атомами вуглецю у вихідних кристалічних гратках.

Вуглець, синтезований з карбіду заліза $\mathrm{Fe}_{3} \mathrm{C}$ 3 ромбічною граткою має найменший об'єм мікропор та широкий діапазон розподілу пор за розмірами (від 0,8 до 20 нм). Це є не прийнятним для використання такого вуглецю у обкладинках суперконденсаторів.

\section{Висновки}

Високотемпературне хлорування карбідів різної будови дозволяє отримати нанопористий вуглецевий матеріал з високою питомою поверхнею та контрольованим розміром та розподі- лом пор.

В результаті високотемпературної обробки хлором карбідів 3 кубічною граткою можна отримати високопористий вуглець 3 вузьким розподілом пор за розмірами (від 0,5 до 2 нм).

Найбільший об'єм мікропор (87\%) та при цьому достатньо висока їх питома поверхня $1247 \mathrm{~m}^{2} / \Gamma$ формується у вуглеці 3 карбіду титану з ГЦК граткою.

\section{Бібліографічний список}

1. Шурыгина В. Суперконденсаторы размеры меньше, мощность выше. Электроника : Наука, Технология, Бизнес. 2009. №7. С. 11-20.

2. Simon P., Gogotsi Y. Capacitive energy storage in nanostructured carbon - electrolyte systems. Accounts of chemical research. 2012. V. 46. №. 5. P. 1094-1103. 
3. Ania C. O., Pernak J., Stefaniak F., Raymundo-Pinero E., Beguin F. Solvent-free ionic liquids as in situ probes for assessing the effect of ion size on the performance of electrical double layer capacitors. Carbon, 2006. Vol. 44, Issue 14. P. 3126-3130.

4. Kim Y. T., Lee B. J., Suezaki H., Chino T., Abe, Y., Yanagiura T., Park K.C., Endo M. Preparation and characterization of bamboo-based activated carbons as electrode materials for electric double layer capacitors. Carbon. 2006. Vol. 44, Issue 8. P. 581-616.

5. Guo Y., Qi J., Jiang Y. X., Yang S., Wang Z., Xu H. Performance of electrical double layer capacitors with porous carbons derived from rice husk. Materials Chemistry \& Physics. 2003. 80. P. 704-709.

6. Wu F.-C., Tseng R.-L., Hu C.-C., Wang, C.-C. Physical and electrochemical characterization of activated carbons prepared from firwoods for supercapaictors. J. Power Sources. 2004. 138. P. 351-359.

7. Ковалюк 3. Д., Юрценко С. П., Семенчук I. I. Пористий вуглецевий матеріал 3 рослинної сировини як поляризаційна складова електродів суперконденсаторів. Журнал нано- та електронної фізики. 2015. Том 7. № 2, 02017 (3cc).

8. Endo M., Maeda T., Kim Y. J., Dresselhaus M S., Ohta H., Inoue T., Hayashi T., Nishimura, Y. Morphology and organic edlc applications of chemically activated Ar-resin-based carbons. Carbon, 2002. Vol. 40, Issue 14. P. 2613-2626.

9. Chen J. H., Li W. Z., Wang D. Z., Yang S. X., Wen J. G., Ren Z. F. Electrochemical characterization of carbon nanotubes as electrode in electrochemical double-layer capacitors. Carbon, 2002. Vol. 40, Issue 8. P. 1193-1197.

10. Zhao X., Sanchez B. M., Dobson P. J., Grant P. S. The role of nanomaterials in redoxbased supercapacitors for next generation energy storage devices. Nanoscale. 2011. Issue 3. P. 839855.

11. Presser V., Heon M., Gogotsi Yu. Carbide-Derived Carbons - From Porous Networks to Nanotubes and Graphene Adv. Funct. Mater. 2011. Vol. 21. Issue 5. P. 810-833.

12. Nikitin A., Gogotsi Y. Nanostructured carbide derived carbon. Encyclopedia of Nanoscience and Nanotechnology Edited by H. S. Nalwa. American Scientific Publishers: Stevenson Ranch, CA. 2003. Vol. 7. P. 553-574.
13. Gogotsi Y., Nikitin A., Ye H., Zhou W., Fischer J.E., Yi B., Foley H.C., Barsoum M. W. Nanoporous carbide-derived carbon with tunable pore size. Nat. Mater., 2003. 2. P. 591-594.

14. Kravchik A. E, Kukushkina Ju. A., Sokolov V. V. et al. Structure of nanoporous carbon produced from boron carbide. Carbon. 2006. Vol. 44. P. 3263-3268.

15. Грег С., Синг К. Адсорбция, удельная поверхность, пористость. Москва : Мир, 1984. $312 \mathrm{c}$.

16. Гаврилова Н.Н., Назаров В. В. Анализ пористой структуры на основе адсорбционных данных : учеб. пособие. Москва : РХТУ им. Д. И. Менделеева, 2015. 132 с.

17. Кислый П. С., Кузенкова М. А., Боднарук Н. И., Грабчук Б. Л. Карбид бора. Киев : Наук. думка, 1988. 216 с.

18. Цементит в углеродистых сталях : коллектив. монография / под ред. В. М. Счастливцева. Екатеринбург : Издательство УМЦ УПИ, 2017. $380 \mathrm{c}$.

19. Самсонов Г. В., Виницкий И. М. Тугоплавкие соединения : справочник. Москва : Металлургия, 1976.560 c.

\section{References}

1. Shurygina, V. (2009). Superkondensatory razmery menshe, moshchnost vyshe. Ehlektronika : Nauka, Tekhnologiia, Biznes, (7), 11-20

2. Simon, P., \& Gogotsi, Y. (2012). Capacitive energy storage in nanostructured carbon - electrolyte systems. Accounts of chemical research, 46(5), 1094-1103

3. Ania, C.O., Pernak, J., Stefaniak, F., Raymundo-Pinero, E., \& Beguin, F. (2006). Solventfree ionic liquids as in situ probes for assessing the effect of ion size on the performance of electrical double layer capacitors. Carbon, 2006. 44(14), 3126-3130

4. Kim, Y.T., Lee, B.J., Suezaki, H., Chino, T., Abe, Y., Yanagiura, T., Park, K.C., \& Endo, M. (2006). Preparation and characterization of bamboo-based activated carbons as electrode materials for electric double layer capacitors. Carbon, 44(8), 1592-1595

5. Guo, Y., Qi, J., Jiang, Y.X., Yang, S., Wang, Z., \& Xu, H. (2003). Performance of electrical double layer capacitors with porous carbons derived from rice husk. Materials Chemistry \& Physics, 80(3), 704-709

6. Wu, F.-C., Tseng, R.-L., Hu, C.-C., \& 
Wang, C.-C. (2004). Physical and electrochemical characterization of activated carbons prepared from firwoods for supercapaictors. J. Power Sources, 138(1-2), 351-359

7. Kovalyuk, Z.D., Yurcenko, S.P., Semenchuk, I.I. (2015). Poryctyi vuglycevyi material z roslynnoi syrovyny yak polyaryzaciyna skladova elektrodiv superkondensatoryv. Jurnal nano ta electronnoi fizyky. 7(2), 02017

8. Endo, M., Maeda, T., Kim, Y.J., Dresselhaus, M.S., Ohta, H., Inoue, T., Hayashi, T., \& Nishimura, Y. (2002). Morphology and organic EDLC applications of chemically activated ARresin-based carbons. Carbon, 40 (14), 2613-2626

9. Chen, J.H., Li, W.Z., Wang, D.Z., Yang, S.X., Wen, J.G., \& Ren, Z.F. (2002). Electrochemical characterization of carbon nanotubes as electrode in electrochemical double-layer capacitors. Carbon, 40(8), 1193-1197

10. Zhao, X., Sanchez, B.M., Dobson, P.J., \& Grant, P.S. (2011). The role of nanomaterials in redox-based supercapacitors for next generation energy storage devices. Nanoscale, 3 (3), p. 839855

11. Presser V., Heon M., \& Gogotsi Y. (2011). Carbide-Derived Carbons - From Porous Networks to Nanotubes and Graphene. Adv. Funct. Mater. 21(5), 810-833
12. Nikitin, A., \& Gogotsi, Y. (2003). Nanostructured carbide- derived carbon. Encyclopedia of Nanoscience and Nanotechnology. Edited by $\mathrm{H}$. S. Nalwa. American Scientific Publishers: Stevenson Ranch, CA, Vol. 7, 553-574

13. Gogotsi, Y., Nikitin, A., Ye, H., Zhou, W., Fischer, J.E., Yi, B., Foley, H.C., \& Barsoum, M. W. (2003). Nanoporous carbide-derived carbon with tunable pore size. Nat. Mater., 2, 591-594

14. Kravchik, A.E, Kukushkina, J. A., Sokolov, V.V. et al. (2006). Structure of nanoporous carbon produced from boron carbide. Carbon, 44, 3263-3268

15. Greg, S., \& Sing K. (1984). Adsorbzciya, udelnaya poverhnost, poristist. Moscow : Mir

16. Gavrilov, N. N., \& Nazarov V.V. (2015). Analis poristoy struktury na osnove adsorbzcionnyh dannyh: ucheb. posobie. Moscow: RHTU im. D.I. Mendeleeva

17. Kislyi, P.S., Kuzenkova, M.A., Bodnaruk, N.I., \& Grabchuk, B.L. (1988). Karbid, bora. Kyiv: Nauk.dumka

18. Schstlivceva, V.M. (Ed.). (2017). Cementit $v$ uglerodistyh stalyah: kollektiv. Yekaterinburg : Izdatelstvo UMC UPI

19. Samsonov, G. V., \& Vinnizckiy, I.M. (1976). Tugoplavkie soedineniya. Spravochnik. Moscow. Metallurgiya

Рослик Ірина Геннадіївна, доцент, кандидат технічних наук, професор кафедри покриттів, композиційних матеріалів і захисту металів, Національна металургійна академія України (Дніпро, Україна). E-mail: roslyk67@gmail.com

Загородна Вероніка Валеріївна, аспірант кафедри покриттів, композиційних матеріалів і захисту металів, Національна металургійна академія України (Дніпро, Україна). E-mail: veronika@mrc.org.ua

\section{ДОСЛІДЖЕННЯ ВЛАСТИВОСТЕЙ НАНОПОРИСТОГО ВУГЛЕЦЮ, ОТРИМАНОГО 3 КАРБІДІВ РІЗНОЇ БУДОВИ}

Мета - визначення зв'язку між початковою структурою карбіду та пористою структурою синтезованого з нього вуглецю, а саме розмірами пор, розподілом пор за розмірами та величиною питомої поверхні.

Методика. Нанопористий вуглець одержували високотемпературною обробкою порошків карбідів з різною будовою потоком хлору на експериментальній установці проточного типу. Визначення питомої поверхні та розміру пор виконували на автоматичному обладнанні (Quantachrome, США) 3 комп’ютерним керуванням та обробкою даних. Для визначення питомої поверхні застосовували метод Брунауера - Еммета-Теллера (БЕТ). Пористу структуру вуглецю, а саме об'єм пор та їх розподіл за розмірами, було визначено на підставі функціональної теорії нелокальної щільності (NLDFT) 3 застосуванням програмного забезпечення.

Результати. Експериментально встановлено, що високопористий вуглець з розподілом розмірів пор в вузькому інтервалі від 0,5 до 2 нм можна отримати з карбідів, що мають кубічну гратку. Самий високий об'єм мікропор та найменший середній розмір пор спостерігається у вуглецю, що отрима- 
ний 3 карбіду титану з гранецентрованою кубічною граткою. Також у нього достатньо висока питома поверхня 1247 м²/г. Вуглець, синтезований з карбіду заліза $\mathrm{Fe}_{3} \mathrm{C} 3$ ромбічною граткою, має найменший об'єм мікропор та самий широкий діапазон розподілу пор за розмірами (від 0,8 до 20 нм).

Наукова новизна. Вперше встановлено що використання карбідів з кубічною граткою забезпечує отримання нанопористого вуглецю з контрольованими розмірами пор у межах від 0,5 до 2 нм та достатньо високою питомою поверхнею.

Практична цінність. Результати роботи можуть бути використані для синтезу вуглецю для виготовлення електродів суперконденсаторів.

Ключові слова: нанопористий вуглець; карбід, високотемпературне хлорування, питома поверхня; розподіл пор за розмірами.

Iryna Roslyk, Candidate of Technical Sciences, Associate Professor of Department of Coatings, composite materials and metal protection, National Metallurgical Academy of Ukraine (Dnipro, Ukraine). Email: roslyk67@gmail.com

Veronica Zahorodna, postgraduate student of Department of Coatings, composite materials and metal protection, National Metallurgical Academy of Ukraine (Dnipro, Ukraine). E-mail: veronika@mrc.org.ua

\section{RESEACH OF NANOPOROUS CARBON PROPERTIES OBTAINED FROM CARBIDES OF DIFFERENT STRUCTURE}

Purpose. The research was aimed to determine the connection between the initial structure of carbide and the porous structure of the carbon synthesized from it, in particular the pores size, the distribution of pores by size and size of the specific surface area.

Methods. Nanoporous carbon was obtained by high-temperature chlorine treatment of carbide powders with different structure on an experimental flow-type installation. The specific surface area and pore size have been determined using automatic equipment (Quantachrome, USA) with computer control and data processing. To determine the specific surface, the Brunauer - Emmett - Teller (BET) method has been used. The porous structure of carbon, namely the pore volume and its size distribution, has been determined on the basis of the non-local density functional theory (NLDFT) using the software which is supplied with the device.

Results. It has been experimentally established that highly porous carbon with a pore size distribution in a narrow range from 0.5 to $2 \mathrm{~nm}$ can be obtained from carbides having a cubic lattice. The highest volume of micropores and the smallest average pore size is observed in carbon obtained from titanium carbide with a face-centered cubic lattice. It also has a fairly high specific surface area of $1247 \mathrm{~m}^{2} / \mathrm{g}$. Carbon synthesized from $\mathrm{Fe}_{3} \mathrm{C}$ iron carbide with a rhombic lattice has the smallest volume of micropores and the widest range of pore size distribution (from 0.8 to $20 \mathrm{~nm}$ ).

Originality. It has been found for the first time that the use of carbides with a cubic lattice provides nanoporous carbon with controlled pore sizes in the range from 0.5 to $2 \mathrm{~nm}$ and a sufficiently high specific surface area.

Practical implications. The research results can be used for the synthesis of carbon for the manufacture of supercapacitor electrodes.

Key words: nanoporous carbon; carbide, high-temperature chlorination, specific surface area; pore size distribution.

Рослик Ирина Геннадиевна, доцент, кандидат технических наук, профессор кафедры покрытий, композиционных материалов и защиты металлов, Национальная металлургическая академия Украины (Днепр, Украина). E-mail: roslyk67@gmail.com

Загородная Вероника Валериевна, аспирант кафедры покрытий, композиционных материалов и защиты металлов, Национальная металлургическая академия Украины (Днепр, Украина). E-mail: veronika@mrc.org.ua 


\section{ИССЛЕДОВАНИЕ СВОЙСТВ НАНОПОРИСТОГО УГЛЕРОДА, ПОЛУЧЕННОГО ИЗ КАРБИДОВ РАЗЛИЧНОГО СТРОЕНИЯ}

Цель - определение связи между начальной структурой карбида и пористой структурой синтезированного из него углерода, а именно размерами пор, распределением пор по размерам и величине удельной поверхности.

Методика. Нанопористый углерод получали высокотемпературной обработкой порошков карбидов с разным строением потоком хлора на экспериментальной установке проточного типа. Определение удельной поверхности и размера пор выполняли на автоматическом оборудовании (Quantachrome, США) с компьютерным управлением и обработкой данных. Для определения удельной поверхности применяли метод Брунауэра - Эммета-Теллера (БЭТ). Пористую структуру углерода, а именно объем пор и их распределение по размерам, был определен на основании функциональной теории нелокальной плотности (NLDFT) с применением программного обеспечения.

Результаты. Экспериментально установлено, что высокопористый углерод с распределением размеров пор в узком интервале от 0,5 до 2 нм можно получить из карбидов, имеющих кубическую решетку. Самый высокий объем микропор и наименьший средний размер пор наблюдается у углерода, полученного из карбида титана с гранецентрированной кубической решеткой. Также у него достаточно высокая удельная поверхность 1247 м²/г. Углерод, синтезированный из карбида железа $\mathrm{Fe}_{3} \mathrm{C} \mathrm{c}$ ромбической решеткой, имеет наименьший объем микропор и самый широкий диапазон распределения пор по размерам (от 0,8 до 20 нм).

Научная новизна. Впервые установлено, что использование карбидов с кубической решеткой обеспечивает получение нанопористого углерода с контролируемыми размерами пор в пределах от 0,5 до 2 нм и достаточно высокой удельной поверхностью.

Практическая ценность. Результаты работы могут быть использованы для синтеза углерода для изготовления электродов суперконденсаторов.

Ключевые слова: нанопористый углерод; карбид, высокотемпературное хлорирование, удельная поверхность; распределение пор по размерам.

Рукопис надійшов 18.01.2020 